\title{
ON THE MEASURE OF ENTROPY VALUE OF EXTERNAL DEBT STRUCTURE FOR AN ECONOMY
}

V. U. EKHOSUEHI and A. A. OSAGIEDE

(Received 27 April, 2006; Revision Accepted 13 July, 2006)

\begin{abstract}
This paper considers the use of external debt structure to measure the stability of an economy. This is achieved by modifying the existing entropy model to capture the debt service ratio. The modified entropy model is then used to estimate the entropy value of the Nigerian economy
\end{abstract}

KEYWORDS: debt service ratia; development planning; entropy; likelihood function.

\section{$1.0 \quad$ INTRODUCTION}

To accelerate the rate of economic development, less developed countries (LDCs) borrow to import capital goods, components, raw materials, technical - know - how, etc (Jhingan, 2003). Repayment of this loan and interest constitutes external debt. Anyanwu (1997) stipulated that, to manage external debt effectively, authorities must project the time profile of debt service obligation, they must accurately forecast export earnings, domestic revenues and future access to finance. Iyoha (2004) maintains that external debts has a deleterious effect on economic growth and clevelopment (also see Obadan, 2002, lyoha, 2005, and lyoha, 2002).

McClean and Abodunde (1978) define entropy as the thermodynamic variable of the system under consideration. They also view entropy as a measure of "the number of ways in which the elementary particles of the system may be arranged in the given circumstances". Entropy has been used in the study of manpower system, combat degradation and queuing systems (see Omosigho and Osagiede, 1999).

In this paper, we modify the model of McClean and Abodunde (1978) to capture the debt service ratio to estimate entropy of the Nigerian economy based on the external debt structure. We do this by using data on external debt outstanding from 1983 to 1996 , and the debt service ratio for the same period

\subsection{BASIC ENTROPY FOR MANPOWER SYSTEM}

McClean and Abodunde (1978) used entropy to measure the stability of the length of service in a system by applying the formula:

$$
H=\frac{-\sum_{1=1}^{k} P_{1} \log P_{1}}{\log k}
$$

where $k$ is the maximum number of tenure classes:

$P_{i}$ is the probability that a member of staff is in tenure class $i$

The tenure profile, for a firm, is defined as the proportion of staff in each length of service class.

Entropy, $H_{1}$ lies in the closed interval $[0,1] . H=0$ when $P_{1}=1$ and $P_{2}=P_{3}=\ldots=P_{k}=0$ and $H=1$ only when $P_{1}=P_{2}=\ldots=P_{k}=1 / k$. Low entropy (i.e $0 \leq H<0.5$ ) implies instability, while high entropy, for $0.5 \leq H \leq 1$, indicates stability in the organization. Omosigho and Osagiede (1999) stated that, when $0<\mathrm{H}<1$, the entropy is a good measure of the distribution of experience in the organization

\section{MODEL DEVELOPMENT}

Rostow (1960) as cited by Jhingan (2003) distinguished five stages of economic growth, viz: the traditional society, the pre - conditions for take - off, the take - off, the drive to maturity, and the age of high mass consumption. Okojie (2002) categorises development planning in Nigeria since the post - independence period into the following

- Fixed medium -term planning in Nigeria

First National Development Plan, 1962 - 1968:

Second National Development Plan, 1970-1974;

Third National Development Plan, 1975 - 1980:

Fourth Nationai Development Plan, $1981-1985$

- The Structural Adjustment Programme Period, 1986 - 1988

- Perspective Planning in Nigeria

The First National Rolling Plan, 1990 - 1992; and

Vision 2010, $1997-2010$ 
In the light of the stages of development, an entropy formula can be developed for an economy. Let each stage of development represent the tenure class.

Let the debt level in stage $i$ owed to creditor $j$ during period $t$ be denoted by $n_{i j}(t)$. Let $P_{i j}(t)$ be the probability of debt in stage l owed to creditor $j$ during period $t, i=1,2, \ldots, m ; j=1,2, \ldots, r$ and $t=1,2, \ldots n$,

Where $m$ is the maximum developmental stage, $r$ is the $t$ th creditor and $n$ is the maximum period for which data are available.

Omosigho and Osagiede (1999) posited that the estimation of entropy is normally based on the use of relative frequencies as probabilities without proof. With a view to validating this statement, we assume that the distribution of the system is multinomial, so that we can write

$$
P\left(n_{11}(t), n_{t 2}(t), \ldots, n_{t r}(t)\right)=\frac{\left(\sum_{i=1}^{r} n_{t i}(t)\right) !}{\prod_{j=1}^{r}\left(n_{t j}(t)\right) !} \prod_{t=1}^{r} P_{t j}^{n_{t \prime}(t)}(t)
$$

(see Uche and Ezepue, 1991)

Using the likelihood function as stated in Lindgren (1993), it is easy to see that,

$$
\hat{P}_{i l}(t)=\frac{n_{y}(t)}{n_{1}(t)}, i=1,2, \ldots, m, j=1,2, \ldots, r ; t=1,2, \ldots, n
$$

where $n_{i}(t)$ is the debt level in stage $i$ in period $t$.

The maximum likelihood estimates of $P_{i j}$ is obtained by pooling the results in equation (3). That is

$$
\hat{P}_{\prime \prime}=\frac{\sum_{t=1}^{n} n_{l i}(t)}{\sum_{i=1}^{n} n_{i}(t)}
$$

Besides, the effect of Nigeria's escalating external debt has been aggravated by domestic macroeconomic policy deficiencies which have resulted in a stagnating income per capita, uneven growth of real gross domestic product (GDP) and rising inflation (lyoha, 2005). Accompanying the escalating external debt has been a crushing debt - service burden (lyoha, 2005). High debt - service ratios make the country extremely vulnerable to pressures on its balance of payments, thus hampering the development effort (lyoha, 2002, 2004. 2005, and Obadan, 2002).

We therefore modify the formula in equation (1) to capture the debt service ratio as

$$
H^{*}=\frac{1}{2 m} \sum_{i=1}^{m} \sum_{i=1}^{r}\left(\frac{\alpha_{11}}{r}-\frac{P_{11} \log P_{11}}{\log r}\right)
$$

where $\alpha_{l \prime}$ is the debt service ratio in the ith developmental stage to the jth creditor. Debt service ratio is the ratio of debt - service payment to exports of goods and services.

$\mathrm{H}^{*}=0$ if $\mathrm{P}_{\mathrm{i} 1}=1, \mathrm{P}_{\mathrm{i} 2}=\mathrm{P}_{\mathrm{i} 3}=\ldots=\mathrm{P}_{\mathrm{ir}}=0$ and $\alpha_{11}=0$ for all $\mathrm{i}$. This means that all debt were owed to creditor 1 (say) through out the various developmental stages, but the economy failed to service her debt. This indicates a severe economic instability, since the debt stock increases as a result of interest, and the economy possibly experiences debt overhang problem.

$$
H^{*}=1 \text { if } P_{11}=\frac{1}{r} \text { for every } i, j \text {, which means that there exists a uniform limit on total external borrowing from }
$$

each creditor $\mathrm{j}$, and the receipts from export of goods and services are used for debt service payment i.e. $\alpha_{i j}=1$ This implies stability. Thus, for economic stability, the rate at which external debt is secured should be related to the foreign exchange earning capacity of the nation (see Anyanwu, 1997). The notation $\alpha$, is given by

$$
\alpha_{1}=\sum_{i=1}^{r} \alpha_{11}
$$

\subsection{APPLICATION}

1996.

The entropy value of the Nigerian economy is calculated using available data for the years between 1983 and

Equation (5) is used to estimate the entropy value. The source of data is from Obadan (2002), but the value for 1986 was not used because it does not add up to the total given (see Table I in List of Tables). Therefore, we obtained the results in Table II (see List of Tables).

The debt service ratio for the ith developmental stage, $\hat{\alpha}_{1}$ is computed from lyoha (2005) by the formula 


$$
\hat{\alpha}_{1}=\frac{\sum_{t=1}^{n_{1}} \alpha_{1}(t)}{n_{1}}
$$

where $n$ depends on $i$ since the periods of the development stage are unequal.

From Table III (see List of Tables), we obtain $\hat{\alpha}_{1}$ as follows:

$$
\hat{\alpha}_{l}=\frac{\sum_{t=1}^{3} \alpha_{1}(t)}{3} \text {. }
$$

where the coding for $t$ is from 1983 to 1985

$$
\hat{\alpha}_{1}=\left(\frac{17.8+29.1+31.7}{3}\right) \%=0.262
$$

Similarly, $\hat{\alpha}_{2}=0.205, \hat{\alpha}_{3}=0.226$ and $\dot{\alpha}_{4}=0.159$ are obtained

By considering each of the developmental stages in Nigeria, we have the following:

$$
H_{1}^{*}=\frac{1}{2}\left(\frac{\hat{\alpha}_{1}}{r}-\frac{\sum_{i=1}^{r} P_{11} \log P_{\|}}{\log r}\right)
$$

For the period 1983 to 1985 , a period of fixed medium - term planning in Nigeria, we have

$$
H_{1}^{*}=\frac{1}{2}\left(\frac{0.262}{5}+\frac{1.4427}{\log _{e} 5}\right)=0.4744
$$

(see Table II in List of Tables)

Similarly, for the SAP period. $H_{2}^{*}=0.4524$

$$
\text { the rolling plan period, } H_{3}^{*}=0.4217 \text {, }
$$

and the perspective planning period, $H_{4}^{*}=0.3565$

Therefore, the entropy of the Nigerian economy from 1983 to 1996 can be estimated from the formula in equation (5) as

$$
\begin{aligned}
H^{*} & =\frac{1}{2 m} \sum_{i=1}^{m} \sum_{j=1}^{r}\left(\frac{\hat{\alpha}_{y}}{r}-\frac{P_{11} \log P_{i f}}{\log r}\right) \\
& =\frac{1}{m} \sum_{i=1}^{m} \frac{1}{2}\left(\frac{\hat{\alpha}_{1}}{r}-\frac{\sum_{t=1}^{r} P_{i j} \log P_{i j}}{\log r}\right)
\end{aligned}
$$

Thus, for $m=4$ and $r=5$,

$$
\begin{aligned}
H^{*} & =\frac{1}{4}(0.4744+0.4524+0.4217+0.3565) \\
& =0.4263 .
\end{aligned}
$$


Table I: Structure of External Public Debt Outstanding, 1983 - 96 (US \$ million)

\begin{tabular}{|c|c|c|c|c|c|c|c|}
\hline & 1983 & 1984 & 1985 & 1986 & 1987 & 1988 & 1989 \\
\hline Multilateral & 884 & 1097 & 1317 & 1887 & 2985 & 2838 & 3171 \\
& $(5.0)$ & $(6.3)$ & $(7.0)$ & $(7.4)$ & $(10.50)$ & $(9.2)$ & $(10.0)$ \\
\hline Paris Club & 5390 & 5811 & 7833 & 12589 & 12589 & 14400 & 15871 \\
& $(30.3)$ & $(33.5)$ & $(41.4)$ & $(44.5)$ & $(44.5)$ & $(46.9)$ & $(50.2)$ \\
\hline London Club & 6263 & 4996 & 3560 & 5860 & 5860 & 5960 & 5680 \\
& $(35.3)$ & $(28.8)$ & $(18.8)$ & $(20.7)$ & $(20.7)$ & $(19.4)$ & $(180)$ \\
\hline Promissory & 3702 & 4125 & 4255 & 4850 & 4850 & 4810 & 4553 \\
Notes & $(20.8)$ & $(23.8)$ & $(22.5)$ & $(17.1)$ & $(17.1)$ & $(15.7)$ & $(14.4)$ \\
\hline Others & 1526 & 1318 & 1939 & 2032 & 2032 & 2685 & 2311 \\
& $(8.6)$ & $(7.6)$ & $(10.2)$ & $(7.2)$ & $(7.2)$ & $(8.7)$ & $(7.3)$ \\
\hline TOTAL & 17765 & 17347 & 18904 & 28316 & 28316 & 30693 & 31586 \\
\hline & & & & & & & \\
\hline & 1990 & 1991 & 1992 & 1993 & 1994 & 1995 & 1996 \\
\hline Multilateral & 3842 & 3650 & 4518.0 & 36947 & 4402.3 & 4411.0 & 4665.0 \\
& $(11.6)$ & $(10.9)$ & $(16.4)$ & $(12.9)$ & $(14.9)$ & $(13.5)$ & $(16.6)$ \\
\hline Paris Club & 17171 & 17793 & 164339 & 18160.5 & 18334.3 & 21669.6 & 19019.0 \\
& $(51.9)$ & $(53.3)$ & $(60.0)$ & $(63.2)$ & $(62.3)$ & $(66.5)$ & $(68.0)$ \\
\hline London Club & 5861 & 5988 & 2120.0 & 2055.8 & 2057.8 & 2045.0 & 2043.0 \\
& $(17.7)$ & $(17.9)$ & $(7.7)$ & $(13.97)$ & $(6.9)$ & $(6.3)$ & $(7.3)$ \\
\hline Promissory & 4550 & 4479 & 3246.0 & 3159.9 & 3178.2 & 3148.0 & 2140.0 \\
Notes & $(13.7)$ & $(13.4)$ & $(11.8)$ & $(11.0)$ & $(10.8)$ & $(9.7)$ & $(7.6)$ \\
\hline Others & 1675 & 1454 & 1246.9 & 1647.3 & 1456.3 & 1311.2 & 121.0 \\
& $(5.1)$ & $(4.4)$ & $(4.4)$ & $(5.7)$ & $(49)$ & $(4.0)$ & $(0.04)$ \\
\hline TOTAL & 33099 & 33364 & 27564.8 & 28718.2 & 29428.9 & 32584.8 & 28060.0 \\
\hline
\end{tabular}

Note: Figures in parentheses are percentage shares while those above them are in million US doliars Source: Obadan, 2002, citing from CBN Annual Report.

Table II:

Probability Estimates for Various Stages

\begin{tabular}{|c|c|c|c|c|c|c|}
\hline & \multicolumn{3}{|c|}{ Fixed Medium - Term Plan } & \multicolumn{3}{|c|}{ SAP Period } \\
\hline \begin{tabular}{ll} 
& \multicolumn{1}{c}{ Creditor j } \\
1. & Multilateral \\
2. & Paris Club \\
3. London Club \\
4. Promisory Note \\
5.
\end{tabular} & $\begin{array}{c}\mathbf{P}_{\mathrm{ij}} \\
0.0611 \\
0.3524 \\
0.2743 \\
0.2237 \\
0.0885\end{array}$ & $\begin{array}{l}\log P_{i j} \\
-2.7960 \\
-1.0431 \\
-1.2934 \\
-1.4976 \\
-2.4242\end{array}$ & $\begin{array}{l}P_{i j} \log P_{i j} \\
-0.1708 \\
-0.3676 \\
-0.3548 \\
-0.3350 \\
-0.2145\end{array}$ & $\begin{array}{c}P_{2 i} \\
0.0993 \\
0.4731 \\
0.1932 \\
0.1569 \\
0.0776\end{array}$ & $\begin{array}{l}\log P_{2 j} \\
-2.3098 \\
-0.7485 \\
-1.6442 \\
-1.8522 \\
-2.5565\end{array}$ & $\begin{array}{l}P_{2 i} \log P_{2 i} \\
-0.2294 \\
-0.3541 \\
-0.3177 \\
-0.2906 \\
-0.1984\end{array}$ \\
\hline Total & & & -1.4427 & & & -1.3902 \\
\hline
\end{tabular}

\begin{tabular}{|c|c|c|c|c|c|c|}
\hline \multicolumn{9}{|c|}{ Rolling Plan } & \multicolumn{3}{c|}{ Perspective Plan } \\
\hline & & & & & & \\
\hline & $P_{3 i}$ & $\log P_{3 i}$ & $P_{3 i} \log P_{3 i}$ & $P_{41}$ & Log $P_{4 i}$ & $P_{4 i} \log P_{4 i}$ \\
\hline 1 & 0.1277 & -2.0579 & -0.2628 & 0.1446 & -1.9340 & -0.2797 \\
2 & 0.5466 & -0.6040 & -0.3301 & 0.6497 & -0.4312 & -0.2801 \\
3 & 0.1486 & -1.9067 & -0.2833 & 0.0690 & -2.6730 & -0.1844 \\
4 & 0.1305 & -2.0360 & -0.2657 & 0.0979 & -2.3241 & -0.2275 \\
5 & 0.0465 & -3.0675 & -0.1426 & 0.0382 & -3.2654 & -0.1247 \\
\hline Total & & & & & & \\
\hline
\end{tabular}




\begin{tabular}{|c|c|c|c|c|}
\hline Year & $\begin{array}{l}\text { External Debt } \\
\text { (US \$ Million) }\end{array}$ & $\begin{array}{l}\text { Debt Per Capital } \\
\text { (US \$) }\end{array}$ & $\begin{array}{c}\text { Debt / GDP Ratio } \\
\text { (Percentage) }\end{array}$ & $\begin{array}{c}\text { Debt Service Ratio } \\
\text { (Percentage) }\end{array}$ \\
\hline 1971 & 309 & 64 & 2.7 & 23 \\
\hline 1972 & 401 & 8.0 & 3.7 & 1.8 \\
\hline 1973 & 421 & 8.2 & 2.5 & 18 \\
\hline 1974 & 523 & 9.8 & 1.8 & 13 \\
\hline 1975 & 559 & 10.2 & 16 & 0.5 \\
\hline 1976 & 594 & 10.5 & 1.4 & 0.7 \\
\hline 1977 & 763 & 131 & 1.1 & 0.3 \\
\hline 1978 & 2164 & 361 & 3.5 & 27 \\
\hline 1979 & 2825 & 45.6 & 3.7 & 17 \\
\hline 1980 & 3444 & 532 & 3.7 & 08 \\
\hline 1981 & 3668 & 549 & 4.6 & 50 \\
\hline 1982 & 13124 & 1919 & 17.1 & 8.9 \\
\hline 1983 & 17765 & 2513 & 18.5 & 178 \\
\hline 1984 & 17347 & 237.6 & 23.3 & 29.1 \\
\hline 1985 & 18904 & 250.4 & 239 & 31.7 \\
\hline 1986 & 25574 & 328.3 & 56.7 & 28.0 \\
\hline 1987 & 28316 & 351.8 & 92.6 & 11.9 \\
\hline 1988 & 30693 & 3689 & 92.2 & 24.2 \\
\hline 1989 & 31589 & 3721 & 106.9 & 25.3 \\
\hline 1990 & 33099 & 381.8 & 114.6 & 23.9 \\
\hline 1991 & 33730 & 381.1 & 101.4 & 25.7 \\
\hline 1992 & 27565 & 302.9 & 99.0 & 18.2 \\
\hline 1993 & 28718 & 305.5 & 90.8 & 16.2 \\
\hline 1994 & 29429 & 304.0 & 71.1 & 18.8 \\
\hline 1995 & 32585 & 327.5 & 36.7 & 15.2 \\
\hline 1996 & 28060 & 274.6 & 22.5 & 13.4 \\
\hline 1997 & 27087 & 258.0 & 21.0 & 10.9 \\
\hline 1998 & 28773 & 265.4 & 22.9 & 16.1 \\
\hline 1999 & 28039 & 179.3 & 77.2 & 9.0 \\
\hline 2000 & 28274 & 245.4 & 86.4 & 9.0 \\
\hline 2001 & 28347 & 236.6 & 57.9 & 11.9 \\
\hline 2002 & 30990 & 253.7 & 62.3 & 7.5 \\
\hline $2003^{*}$ & 32917 & 261.3 & 64.4 & 9.8 \\
\hline
\end{tabular}

\section{* Estimated}

Source:

lyoha (2005) citing from Debt Management Office Nigeria, 2004. Annual Report and State of Account for the year ended December 31st. 2003.

\subsection{DISCUSSION}

From the analysis in section 4.0, $H^{*}=0.4263$. This result shows an economic instability for the Nigerian economy. This may be as a result of accumulated interest arising from the debt. Additionally, there is a strong empirical evidence of the negative effect of high external debt for the Nigerian economy, as $H^{*}$ is low, and low debt service ratio, $\alpha_{i}$, below $30 \%$ in the period under study. This is in line with Anyanwu (1997); lyoha $(2002 ; 2004 ; 2005)$ and Obadan (2002). This result also illustrates a declining trend in the level of stability in the Nigerian economy as indicated by the values of $H_{i}^{*}$. It is worthy of note that the adoption of the Structural Adjustment Programme did not remedy the situation as indicated by the low value of $H_{2}^{*}\left(H_{2}^{*}=0.4524\right)$. 


\subsection{CONCLUSION}

We have applied entropy to measure the external debt structure of an economy with Nigeria as a case study. The basic entropy model is modified to accommodate some variables as the debt service ratio as well as developmental stages in the economy. The low entropy value obtained in this work signifies low debt servicing and hence economic instability. Therefore. we suggest that the government should formulate macroeconomic policies to facilitate payment of debt.

\section{ACKNOWLEDGEMENT}

The authors gratefully acknowledge the diligence and useful comments of the anonymous referee that resulted to the quality of work in this study.

\section{REFERENCES}

Anyanwu, J. C., 1997 "Nigerian Public Finance" Joanes Educational Publishers, Onitsha.

Iyoha, M. A., 2002. "An Overview of Leading Issues in the Structure and Development of the Nigerian Economy Since 1960". In M. A. lyoha and C. O. Itsede (Eds) Nigerian Economy: Structure, Growth and Development Mindex, Benin City.

Iyoha, M. A., 2004. "Macroeconomics. Theory and Policy" Mindex, Benın City

Iyoha, M. A., 2005. "When Will Africa's Sleeping Giant Awake?" Inaugural Lecture Series 75, University of Benin, May, 19, 2005. Uniben Press.

Jhingan, M. L., 2003. "The Economics of Development and Planning" (36th Ed.) Vrinda Publications (P) Ltd., Delhi.

Lindgren, B. W., 1993. "Statistical Theory". (4th Ed.) Chapman and Hall, New York.

McClean, S. and Abodunde, T., 1978. Entropy as a Measure of Stability in a Manpower System. J. Opl. Res. Soc. Vol. 29 , No. 9. $885-889$

Obadan, M. I., 2002. "External Debt and Management Policy". In M. A. Iyoha and C. O. Itsede (Eds.), Nigerian Economy: Structure, Growth and Development. Mindex, Benin City

Okojie, C. E. E, 2002. "Development Planning in Nigeria Since Independence" In M. A. Iyoha and C. O. Itsede (Eds.), Nigerian Economy: Structure, Growth and Development Mindex, Benin City.

Omosigho, S. E. and Osagiede. A. A., 1999. "On Estımation of Entropy Value for an Organisation" Journal of the Nigerian Association of Mathematical Physics. Vol 3. No $3 \quad 36-42$.

Rostow, W.W., 1960. "Rostow's Stages of Economic Growth" In Jhingan, ML., 2003, The Economics of Development and Planning (36th Ed.). Vrinda Publications (P) Ltd., Delhi. 123-136pp.

Uche, P. I. and Ezepue, P. O., 1991. "The Markovian Model of Academic Staff Flow in a Tertiary Institution". Jour. Nig. Statist. Assoc. Vol. 6, No. 1. $49-68$. 